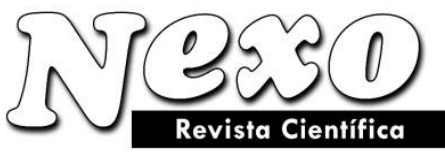

ISSN-E 1995-9516

Universidad Nacional de Ingeniería COPYRIGHT @ (UNI). TODOS LOS DERECHOS RESERVADOS

http://revistas.uni.edu.ni/index.php/Nexo https://doi.org/10.5377/nexo.v33i01.10052

\title{
NANO DRUG DELIVERER FOR AMPICILLIN, CLAVULANIC ACID, IMIPENEM, PENICILLIN G AND TICARCILLIN
}

\section{DISTRIBUIDOR DE MEDICAMENTOS NANO PARA AMPICILINA, ÁCIDO CLAVULÁNICO, IMIPENEM, PENICILINA G Y TICARCILINA}

\author{
Maryam Derakhshandeh $^{1}$, Majid Monajjemi ${ }^{2 *}$ \\ ${ }^{1}$ Department of chemistry, Science and research branch, Islamic Azad University, Tehran, Iran \\ ${ }^{2}$ Department of Chemical engineering, central Tehran Branch, Islamic Azad University, Tehran, Iran \\ Maj.monajjemi@iauctb.ac.ir
}

(recibido/received: 07-enero-2020; aceptado/accepted: 17-marzo-2020)

\begin{abstract}
Ampicillin belonging to the penicillin group of beta lactam antibiotics. Ampicillin is able to penetrate Gram positive and some Gram-negative bacteria. Imipenem (Primaxin) is an intravenous $\beta$-lactam antibiotic discovered by Merck scientists Burton Christensen, William Leanza, and Kenneth Wildonger in 1980 Ampicillin, Clavulanic acid, Imipenem, Penicillin G and Ticarcillin properties for the drug delivery with binding to SWCNNTs and SWBNNTs have been studied. Penicillin and its alteration Penicillin G or phenoxyacetic acid for Penicillin V is used for large scale production. Penicillin and other cell wall inhibitors are primarily specific against Gram positive bacteria because of higher percentage of peptidoglycan in the cell walls of these organisms. It was the first member of the carbapenem class of antibiotics. Based on our previous works we have modeled and simulated a drug delivery system of those antibiotics. The investigation of those antibiotics in binding with single-walled carbon nanotube (SWCNT) and SWBNNTs have been studied by theoretical methods. It has been established the best structural and functional of those antibiotics.
\end{abstract}

Keyword: Ampicillin; Clavulanic acid; Imipenem; Penicillin G; Ticarcillin; DFT; NMR; SWCNTs; SWBNNTs; drug delivery.

\section{RESUMEN}

La ampicilina que pertenece al grupo de antibióticos betalactámicos de penicilina. La ampicilina puede penetrar bacterias Gram positivas y algunas bacterias Gram negativas. Imipenem (Primaxin) es un antibiótico intravenoso de $\beta$-lactámicos descubierto por los científicos de Merck Burton Christensen, William Leanza y Kenneth Wildonger en 1980. Las propiedades de la Ampicilina, ácido clavulánico, Imipenem, Penicilina G y Ticarcilina para la distribución con ligamento a SWCNNTs and SWBNNTs han sido estidiada. Penicilina y su alteración la penicilina $\mathrm{G}$ o el ácido fenoxiacético para la penicilina V se 
utilizan para la producción a gran escala. La penicilina y otros inhibidores de la pared celular son principalmente específicos contra las bacterias Gram positivas debido al mayor porcentaje de peptidoglucano en las paredes celulares de estos organismos. Fue el primer miembro de la clase de antibióticos carbapenem. En base a nuestros trabajos anteriores, hemos modelado y simulado un sistema de administración de medicamentos con esos antibióticos. La investigación de esos antibióticos en la unión con nanotubos de carbono de pared simple (SWCNT) y SWBNNT han sido estudiada por métodos teóricos. Se ha establecido el mejor estructural y funcional de esos antibióticos.

Palabra clave: Ampicilina; Ácido clavulánico; Imipenem; Penicilina G; Ticarcilina; DFT; RMN; SWCNT; SWBNNT; Suministro de medicamentos.

\section{INTRODUCTION}

Antibiotics are specific chemical substance produced (or derived) by living organisms that are capable of inhibiting the life processes of other organisms (Genc, 2008). Sulfonamides were the first antimicrobial to be developed and their discovery laid the foundation for many of the concepts and techniques used in modern drug discovery. Sulfonamide - based compounds were extensively used for antibacterial agents and are the second antimicrobial agents. Moreover, Antibiotics are widely used in human and veterinary medicine for the prevention and treatment of bacterial infectious diseases. An important but often disregarded aspect of antibiotic use is the fate of antibiotic residues entering the environment. The investigation of sulfonamides intra single walled carbon nanotube (SWCNT) has been studied by theoretical methods (Ogden, 2001). It has been established the best structural and functional of sulfonamide. A test, resulting in the classification of bacteria, has developed by "Hans Christian Gram" (a Danish microbiologist) including gram positive bacteria and gram negative bacteria. Antibiotics are specific chemical substances derived from or produced by living organisms that are capable of inhibiting the life processes of other organisms. The first antibiotics were isolated from "micro-organisms" but some are now obtained from higher plants and animals. Over 3,000 antibiotics have been identified but only a few dozen are used in medicine. Currently there are several classifications of antibiotics which can be summarized as various groups such as (1)-Benzyl-penicillin which are including Penicillin G, benzyl - penicillin sodium, procaine benzyl - penicillin, benzathine penicillin (2) - anti-staphylococcal penicillin (3) - Phenoxypenicillins including Penicillin V and Propicillin Oxacillin, Dicloxacillin and Flucloxacillin (4) - Quinolones including Group I:Norfloxacin Group II: Enoxacin, Norfloxacin, Ciprofloxacin, Group III:Levofloxacin, Group IV: Moxifloxacin (5) - B - Lactam / B-lactamase inhibitors including Ampicillin, Amoxicillin, Mezlocillin, Piperacillin, Ampicillin/sulbactam, Amoxicillin / clavulanate, Piperacillin/ tazobactam and Sulbactam in free combinations (6) - Cephalosporins (third and fourth generation) including Cefotaxime, Ceftriaxone, Ceftazidime, Cefepime, Cefixime (oral), Cefpodoximeproxetil (oral), Ceftibuten (oral) (7) Azol derivatives including Miconazole, Ketoconazole, Fluconazole, Itraconazole, Voriconazole, Posaconazole (8)- Macrolides including Erythromycin, Spiramycin, Roxithromycin, Clarithromycin, Azithromycin (9) - Echinocandins including Caspofungin, Anidulafungin, Micafungin (10)Aminoglycosides including Streptomycin, Gentamicin, Tobramycin, Netilmicin, Amikacin. In the past years (decades), pharmaceutical antibiotics were recognized and sensitized as emerging soil pollutants. Compounds such as sulfonamides and tetra-cyclins reach agricultural land mostly through infected dung from medicated chattels used as muck. Pharmaceutical antibiotics are a large group (structurally diverse compound classes) that comprise mostly ionize and polar able compounds (Nishimori, 2005). Hence, their soil adsorption behavior swerved from that of "well-studied" hydrophobic organic pollutants. In addition to "hydrophobic" interactions, antibiotics may sorb to soils through van der Waals forces, hydrogen bonding, cation exchange, cation bridging, and surface complexes (Beer, 2001). However, sorption can be overcome by investigating either separated natural soil constituents such as "humic" acid or polymers from welldefined "phenolic" compounds, representing specific site and functionality of "humic" substances that can serve as a model to elucidate mode of binding. "Phenolic" compound is a major building block of "humic"

Nexo Revista Científica / Vol. 33, No. 01, pp. 121-136 / Junio 2020 
polymer and was found to polymerize to humus like substance (Nishimori, 2005). Penicillin attach such as penicillin binding protein and interfere with the last step of bacterial cell wall synthesis which is trans peptidase or cross linkage by inhibition of trans peptidase and production of autolysin leads to bactericidal action (Berlin, 1978). The mechanism of action for various antibiotics is different (Kumar, 2009). In view point of bacterial spectrum several points are important such as in effective against organism devoid of peptidoglycan can such as mycobacteria, effective against active organism which synthesizes peptidoglycan cell wall, fungi, viruses and protozoa. Gram positive organisms have cell wall easily traversed by penicillin and therefore they are susceptible to penicillin, several Gram negative organisms have "porin" permit Tran's membrane entry of penicillin and so they are susceptible organisms (EL-Kosasy, 2009). Staphylococci developed resistance to natural Dicloxacillin, penicillin Gand Methicillin which are penicillinase resistance preparations are effective against staphylococci (Boxall, 2004). Combination of penicillins and aminoglycosides has synergistic effect while in view point of absorption; most of them are poorly absorbed after oral administration except amoxicillin and ampicillin. Penicillinase resistant preparation should be given one hour before meals because their absorptions are delayed by presence of food (Li, 1995).

\section{THEORETICAL BACK GROUND}

\subsection{S-NICS METHOD}

Based on our previous works we have investigated a statistical method by computing of nucleusindependent chemical shifts (S-NICS) (Monajjemi, 2015) in point of probes motions in a sphere of shielding and de-shielding spaces of hereto rings in some antibiotics. The reduced anisotropy defined as: $\left[\zeta=\left(\sigma_{z z}-\sigma_{i s o}\right)=\left(\sigma_{33}-\sigma_{i s o}\right)\right](\mathbf{1})$ : Anisotropy $(\Delta \sigma)$ with relation of $\Delta \sigma=\frac{3}{2} \zeta$ including shielding asymmetry $(\eta)$ is defined as: $\eta=\left(\frac{\sigma_{y y}-\sigma_{x x}}{\zeta}\right)=\frac{3\left(\sigma_{y y}-\sigma_{x x}\right)}{2 \Delta \sigma}(2)$ and $\Delta \sigma=\sigma_{z z}-\frac{1}{2}\left(\sigma_{x x}+\sigma_{y y}\right)$ (3). In several cases of an axially symmetric tensor, $\left(\sigma_{y y}-\sigma_{x x}\right)$ will be zero and hence $\eta=0$. However, the asymmetry $(\eta)$ parameter indicates that how much the line figure deviates from an axially symmetric tensor, therefore, $(0 \leq \eta \leq+1)$.

The shielding tensor is expressed as the sum of a symmetric, an anti-symmetric, and a scalar terms, which are ranks 2, 1 and zero tensors which defined as: $\Omega=\Omega^{(0)}+\Omega^{(1)}+\Omega^{(2)}(\mathbf{4})$.

The total chemical shielding tensor $\{r\}$ is a non-symmetric tensor that can be decomposed into three independent tensors as: (1) a traceless symmetric component, (2) an isotropic component, and (3) a traceless anti-symmetric component. In a spherical tensor representation, as Haeberlen have pointed out, at a fundamental level tensors are better represented in spherical fashion, such that a general second-order property “ $\sigma$ " may be written as $\sigma=\sigma^{i s o(0)}+\sigma^{\text {anti(1) }}+\sigma^{\operatorname{sym}(2)}(\mathbf{5})$, where the number in brackets refers to tensor rank. Spherical tensors are intrinsically involved in considering the effects of tensor quantities on density matrix evolution, so the use of this representation is inevitable for such work. It is worth noting that:

$$
\sigma_{0}^{i s o(2)}=\sqrt[2]{3 / 2} \zeta \quad \text { (6) } \quad \sigma_{ \pm 2}^{\text {sym(2) }}=\frac{1}{2} \zeta
$$

The symmetric component of the shielding tensor has tensor elements with $r_{i j}=r_{j i}$. This tensor is responsible for the CSA relaxation most often described in the literature and can be diagonal by rotation into the shielding tensor principal coordinate system. The anti-symmetric tensor also induces CSA relaxation but this is almost impossible to measure because the induced effects are close to parallel to the external magnetic field which cannot be diagonal (Monajjemi, 2010).

By this manuscript, in a statistical calculation we have shown that a time independent average of $\left(\Omega^{*}\right)$ can be replaced of all above sum of asymmetric, an anti-symmetric, and a scalar terms, which are rank 2, rank 1 and rank zero tensors respectively. These methods are based on random motions of probes in the shielding and de-shielding spaces of aromatic and anti-aromatic molecules to consider maximum abundant of

Nexo Revista Científica / Vol. 33, No. 01, pp. 121-136 / Junio 2020 
relaxations points in due to spin-dipole and dipole-dipole interactions. The magnetic environment of a spin is seldom isotropic. Therefore, is represented by a tensor of Span: $(\Omega)=\sigma_{33}-\sigma_{11}$ (8) and $\kappa=$ $\frac{3\left(\sigma_{i s o}-\sigma_{22}\right)}{\Omega}$ (9). In the Herzfeld-Berger notation, tensors have explained by three parameters, which they are combination of the major components in the standard notations. These are including, the span $(\Omega)$, which describes the maximum width of these models, $(\Omega \geq 0)$, and the skew $(\boldsymbol{\kappa})$ of the tensors which are a magnitude of these values. The accurate formulation of the span $(\Omega)$, including the factor of $\left(1-\sigma_{\text {ref }}\right)$ has been described by $\Omega=\left(\sigma_{33}-\sigma_{11}\right)\left(1-\sigma_{\text {ref }}\right)(\mathbf{1 0})$. In the Haeberlen- Mehring- Spiess notation (Mehring, 1978), different combinations of the major components are used for explaining the line figure, and it is needed the major components become orderly according to their segregation from the isotropic value (Monajjemi, 2015, 2014)

\subsection{NMR SHIELDING}

The CSA relaxation rates depend on the anisotropy parameter in the standard parameters, of the shielding tensor, $\left(\sigma_{11}, \sigma_{22}, \sigma_{33}\right)$, are labeled according to the IUPAC rules, and they formalized and adopt the high frequency-positive order. Therefore, $\sigma_{33}$ corresponds to the direction of minimum shielding, with the highest frequency, whenever $\sigma_{11}$ corresponds to the direction of maximum shielding, with the lowest frequency (Monajjemi, 2010).

Moreover the orientation of asymmetry tensor is given by $\left(\kappa=\frac{3 a}{\Omega}\right)$ and the skew is $\kappa=\frac{3\left(\sigma_{150}-\sigma_{22}\right)}{\Omega} ;(-1$ $\leq \kappa \leq+1)$, and related on the position of $\sigma_{22}$ with consideration of $\sigma_{\text {iso }}$, the sign of $\kappa$ is either positive or negative.

In our calculations of various $\mathrm{B}_{\mathrm{n}} \mathrm{N}_{\mathrm{n}}$ Rings, Benzene and naphthalene, $(\kappa)$ is mostly positive, and the negative values are belong to some critical or boundary points. In the case of an axially symmetric tensor, $\sigma_{22}$ equals either $\sigma_{11}$ or $\sigma_{33}$ and $\kappa= \pm 1$ therefore $\boldsymbol{a}=\Omega / 3$, and the parameter " $\boldsymbol{a}$ " and " $\kappa$ " are zero when $\sigma_{22}=\sigma_{\text {iso }}$ and the parameter " $\mu$ " used with the Herzfeld-Berger is related to the span of a tensor. Meanwhile, the spinning rate is given by $\mu=\Omega^{*}$. For a non-zero anti-symmetric tensor give the relaxation rates

and $\rho^{2}$ is defined by:

$$
R_{1}^{d i a, C S A}=\frac{2}{15} \gamma_{s}^{2} B_{0}^{2}\left[5 \rho^{2} \cdot \frac{\tau_{r, 1}}{1+\omega_{s}^{2} \tau_{r, 1}^{2}}+\Delta \sigma^{2}\left(1+\frac{\eta^{2}}{3}\right) \frac{\tau_{r, 2}}{1+\omega_{s}^{2} \tau_{r, 2}^{2}}\right]
$$

$$
\begin{gathered}
\rho^{2}=\left(\frac{\sigma_{x y-} \sigma_{y x}}{2}\right)^{2}+\left(\frac{\sigma_{x z}-\sigma_{z x}}{2}\right)^{2}+\left(\frac{\sigma_{y z}-\sigma_{z y}}{2}\right)^{2} \\
R_{2}^{\text {dia,CSA }}=\frac{2}{45} \gamma_{s}^{2} B_{0}^{2}\left[15 \rho^{2} \cdot \frac{\tau_{r, 1}}{1+\omega_{s}^{2} \tau_{r, 1}^{2}}+\Delta \sigma^{2}\left(1+\frac{\eta^{2}}{3}\right)\left(4 \tau_{r, 2}+\frac{3 \tau_{r, 2}}{1+\omega_{s}^{2} \tau_{r, 2}^{2}}\right)\right]
\end{gathered}
$$

Where $\tau_{r, 1}$ and $\tau_{r, 2}$ correspond to the correlation times for isotropic tumbling and small-step molecular rotation, respectively and in the case of axial symmetry or for isotropic $\tau_{r, 1}=3 \tau_{r, 2}$.

The NMR parameters (such as isotropic magnetic shielding tensors $\left(\sigma_{\text {iso }}\right)$, anisotropic magnetic shielding tensors $\left(\sigma_{\text {aniso }}\right)$ and Chemical shifts $(\delta)$ were also evaluated on the optimized geometries (Sekaran, 2010). .In all calculations the default gauges-including atomic orbital (GIAO) orbitals were used to obtain molecular magnetic susceptibilities, NMR shielding with Gaussian program (Monajjemi, 2014).

\subsection{DENSITY AND ENERGY OF ELECTRONS}

The positive and negative value of this function correspond to electron density is locally depleted and locally concentrated respectively. The relationships between $\nabla^{2} \rho$ and valence shell electron pair repulsion (VSEPR) model, chemical bond type, electron localization and chemical reactivity have been built by Bader (Bader, 1990). 
The electron density has been defined as $\rho(r)=\eta_{i}\left|\varphi_{i}(r)\right|^{2}=\sum_{i} \eta_{i}\left|\sum_{l} C_{l, i} \chi_{i}(r)\right|^{2}(\mathbf{1 4})$. Where $\eta_{i}$ is occupation number of orbital $(i), \varphi$ is orbital wave function, is basis function and $C$ is coefficient matrix, the element of $i_{\text {th }}$ row $j_{\text {th }}$ column corresponds to the expansion coefficient of orbital $j$ respect to basis function $i$. Atomic unit for electron density can be explicitly written as $\mathrm{e} / \mathrm{Bohr}^{3} \cdot \nabla \rho(r)=\left[\left(\frac{\partial \rho(r)}{\partial(x)}\right)^{2}+\left(\frac{\partial \rho(r)}{\partial(y)}\right)^{2}+\left(\frac{\partial \rho(r)}{\partial(z)}\right)^{2}\right]^{\frac{1}{2}}(\mathbf{1 5}) \nabla^{2} \rho(r)=\frac{\partial^{2} \rho(r)}{\partial x^{2}}+\frac{\partial^{2} \rho(r)}{\partial y^{2}}+\frac{\partial^{2} \rho(r)}{\partial z^{2}}(\mathbf{1 6})$ The kinetic energy density is not uniquely defined, since the expected value of kinetic energy operator

$<\varphi\left|-\left(\frac{1}{2}\right) \nabla^{2}\right| \varphi>(\mathbf{1 7})$ Can be recovered by integrating kinetic energy density from alternative definitions. One of commonly used definition is: $k(r)=-\frac{1}{2} \sum_{i} \eta_{i} \varphi_{i}^{*}(r) \nabla^{2} \varphi_{i}(r)$ (18) Relative to $K(\mathbf{r})$, the local kinetic energy definition given below guarantee positivizes everywhere; hence the physical meaning is clearer and is more commonly used.

The Lagrangian kinetic energy density, "G(r)" is also known as positive definite kinetic energy density.

$G(r)=\frac{1}{2} \sum_{i} \eta_{i}\left|\nabla\left(\varphi_{i}\right)\right|^{2}=\frac{1}{2} \sum_{i} \eta_{i}\left\{\left[\left(\frac{\partial \varphi_{i}(r)}{\partial(x)}\right)^{2}+\left(\frac{\partial \varphi_{i}(r)}{\partial(y)}\right)^{2}+\left(\frac{\partial \varphi_{i}(r)}{\partial(z)}\right)^{2}\right]\right\}$ (19). $K(\mathbf{r})$ and $G(\mathbf{r})$ are

directly related by Laplacian of electron density $\frac{1}{4} \nabla^{2} \rho(r)=G(r)-K(r)(\mathbf{2 0})$

Becke and Edgecombe noted that spherically averaged like-spin conditional pair probability has direct correlation with the Fermi hole and then suggested electron localization function (ELF)

[178]. $\operatorname{ELF}(\mathrm{r})=\frac{1}{1+\left[D(r) / D_{0(r)}\right]^{2}}(\mathbf{2 1})$ where $\mathrm{D}(\mathrm{r})=\frac{1}{2} \sum_{i} \eta_{i}\left|\nabla \varphi_{i}\right|^{2}-\frac{1}{8}\left[\frac{\left.|| \nabla \rho_{\alpha}\right|^{2}}{\rho_{\alpha}(r)}+\frac{\left.|| \nabla \rho_{\beta}\right|^{2}}{\beta(r)}\right]$ (22) and

$D_{0(r)}=\frac{3}{10}\left(6 \pi^{2}\right)^{\frac{2}{3}}\left[\rho_{\alpha}(r)^{\frac{5}{3}}+\rho_{\beta}(r)^{\frac{5}{3}}\right](\mathbf{2 3})$ for close-shell system, since $\rho_{\alpha}(r)=\rho_{\beta}(r)=\frac{1}{2} \rho$,

$D$ and $D 0$ terms can be simplified as $\mathrm{D}(\mathrm{r})=\frac{1}{2} \sum_{i} \eta_{i}\left|\nabla \varphi_{i}\right|^{2}-\frac{1}{8}\left[\frac{|\nabla \rho|^{2}}{\rho(r)}\right](\mathbf{2 4}), D_{0(r)}=$

$\frac{3}{10}\left(3 \pi^{2}\right)^{\frac{2}{3}} \rho(r)^{\frac{5}{3}}(\mathbf{2 5})$.

Savin et al. Have reinterpreted ELF in the view of kinetic energy, which makes ELF also meaningful for Kohn-Sham DFT wave-function or even post-HF wave-function. They indicated that $D(\mathbf{r})$ reveals the excess kinetic energy density caused by Pauli repulsion, while $D 0(\mathbf{r})$ can be considered as Thomas-Fermi kinetic energy density.

Localized orbital locator (LOL) is another function for locating high localization regions likewise ELF, defined by Schmider and Becke in the paper (Becke, 1990). $L O L(r)=\frac{\tau(r)}{1+\tau(r)}(\mathbf{2 6})$, where $(r)=\frac{D_{0}(r)}{\frac{1}{2} \sum_{i} \eta_{i}\left|\nabla \varphi_{i}\right|^{2}}(\mathbf{2 7})$.

\subsection{CARBON NANOTUBE (CNT)}

CNT is a representative nano-material. CNT is a cylindrically shaped carbon material with a nanometric-level diameter. Its structure, which is in the form of a hexagonal mesh, resembles a graphite sheet and it carries a carbon atom located on the vertex of each mesh. The sheet has rolled and its two edges have connected seamlessly. Although it is a commonplace material using in pencil leads, its unique structure causes it to present characteristics that had not found with any other materials. CNT can be classified into single-wall CNT, double-wall CNT and multi-wall CNT according to the number of layers of the rolled graphite. The type attracting most attention is the single-wall CNT, which has a diameter deserving the name of "nanotube" of 0.4 to 2 nanometers. The length is usually in the order of microns, but single-wall CNT with a length in the order of centimeters

Nexo Revista Científica / Vol. 33, No. 01, pp. 121-136 / Junio 2020 
has recently released. CNT can be classified into single-wall CNT, double-wall CNT and multiwall CNT according to the number of layers of the rolled graphite. The type attracting most attention is the single-wall CNT, which has a diameter deserving the name of "nanotube" of 0.4 to 2 nanometers. The length is usually in the order of microns, but single-wall CNT with a length about centimeters have recently released. The extremities of the CNT have usually closed with lids of the graphite sheet. The lids consist of hexagonal crystalline structures (six-membered ring structures) and a total of six pentagonal structures (five-membered ring structures) placed here and there in the hexagonal structure. The first report by Iijima was on the multiwall form, coaxial carbon cylinders with a few tens of nanometers in outer diameter. Two years later single walled nanotubes were reported. SWBNNTs have considered as the leading candidate for nano-device applications because of their one-dimensional electronic bond structure, molecular size, and biocompatibility, controllable property of conducting electrical current and reversible response to biological reagents hence SWBNNTs make possible bonding to polymers and biological systems such as DNA and carbohydrates.

\section{COMPUTIONAL DETAILS}

The electron density (Both of Gradient norm \& Laplacian), value of orbital wave-function, electron spin density, electrostatic potential from nuclear atomic charges, electron localization function (ELF), localized orbital locator (LOL defined by Becke (Becke , 1990), total electrostatic potential (ESP), as well as the exchange-correlation density, correlation hole and correlation factor, and the average local ionization energy using the Multifunctional Wave-function analyzer have also been calculated in this study. The contour line map was also drawn using the Multiwfn software (monajjemi, 2015, 2014)

We employed density functional theory with the van der Waals density functional to model the exchange-correlation energies of hetero cages. The double $\zeta$-basis set with polarization orbitals (DZP) were used for x natural gases inside the cages. For non-covalent interactions, the "B3LYP" method is unable to describe van der Waals adsorbed systems by medium-range interactions such as the interactions of two cylinders. The B3LYP and most other functional are correctly insufficient to illustrate the exchange and correlation energy for distant non-bonded medium-range systems. Moreover, some recent studies have shown that inaccuracy for the medium-range exchange energies leads to large systematic errors in the prediction of molecular properties. The charge transfer and electrostatic potential-derived charge were also calculated using the Merz-KollmanSingh, chelp, or chelpG. The charge calculation methods based on molecular electrostatic potential (MESP) fitting are not well-suited for treating larger systems whereas some of the innermost atoms are located far away from the points at which the MESP is computed. Calculations were performed using Gaussian and GAMESS-US packages. The ONIOM methods including three levels from (1)high calculation $(\mathrm{H}),(2)$-medium calculation $(\mathrm{M})$, and (3)-low calculation (L) have been performed in this study. The "advanced DFT" methods are used for high layer of the model and the semi empirical methods of "Pm6" including pseudo=lanl2 and "Pm3MM" are used for the medium and low layers, respectively. The semi empirical method has been used in order to treat the non-bonded interactions between two parts of gases diffused and cages. There are various situations of noncovalent interaction in this system between hydrogen diffused. For non-covalent interactions, the classical "B3LYP" methods are unable to describe van der Waals systems. In this study, we have mainly focused on getting the optimized results for each item from "advanced DFT" methods including the "m06" and "m06-L". The "m062x", "m06-L", and "m06-HF" are a novel Meta hybrid DFT functional with a good correspondence in non-bonded calculations and are useful for

Nexo Revista Científica / Vol. 33, No. 01, pp. 121-136 / Junio 2020 
calculating the energies of the distance between gases and cages. "Pm6", "Extended-Huckel" and "Pm3MM" including pseudo=lanl2 calculations using Gaussian program have done for the nonbonded interaction between two tubs. "M06" and "m06-L (DFT)" functional is based on an iterative solution of the Kohn-Sham equation of the density functional theory in a planewave set with the projector-augmented wave pseudo-potentials. The "Perdew-Burke-Ernzerhof" (PBE) exchange-correlation (XC) functional of the generalized gradient approximation (GGA) is adopted. In such a condition, variations of the innermost atomic charges will not lead towards a significant change of the MESP outside of the molecule, meaning that the accurate values for the innermost atomic charges are not well-determined by MESP outside the molecule. This approach (CHELPG) is shown to be considerably less dependent upon molecular orientation than the original CHELP program. The results are compared to those obtained by using CHELP.

In the CHELPG (Charges from Electrostatic Potentials using a Grid based method), atomic charges are fitted to reproduce the molecular electrostatic potential (MESP at a number of points around the molecule. The MESP is calculated at a number of grid points spaced $3.0 \mathrm{pm}$ apart and distributed regularly in a cube. Charges derived in this way don't necessarily reproduce the dipole moment of the molecule. CHELPG charges are frequently considered superior to Mulliken charges as they depend much less on the underlying theoretical method used to compute the wave function (and thus the MESP). The representative atomic charges for molecules should be computed as average values over several molecular conformations (Schmidtchen, 1997).

\section{RESULT AND DISCUSSION}

In this work, various antibiotics (Fig.1) bonded to different carbon nanotubes including armchair, zigzag and chiral CNTs which have been shown in Fig.2 \& 3. The bond between antibiotics and carbon nanotubes is active in the point of junction while $\mathrm{O}$ is obvious. Besides, the potential of nanotechnology to revolutionize medicine in particular seems endless, and one significant application of this technology is use of carbon nanotubes for the targeted delivery of drug molecules. Antibiotics - CNT is a drug which has been proposed as a therapeutic drug. The calculated isotropic magnetic shielding constants ( $\mathrm{ppm})$, anisotropic magnetic shielding tensors (ppm), Chemical shifts (ppm) and total atomic charges for selected atoms involved in charge transfer of antibiotics - CNT complex in gas phase at GIAO method were compared in Tables 13 . Also, the graphs of calculated isotropic magnetic shielding constants $\sigma_{\text {iso }}(\mathrm{ppm})$, anisotropic magnetic shielding tensors $\sigma_{\text {aniso }}(\mathrm{ppm})$ and Chemical shifts $\delta(\mathrm{ppm})$ versus the number of atomic centers for selected atoms of antibiotics-CNT system were displayed in Fig.4\&5. A quick look at the results reveals that electronegative atoms have maximum anisotropic magnetic shielding constants and small amounts of isotropic magnetic shielding tensors. These can be attributed to the large negative charge of those atoms, which means the high electronic density at the site of nucleus. The $\sigma_{\text {aniso }}$ for those mentioned nucleus are maximum meaning due to relative chemical shifts which are predominantly governed by local diamagnetic shielding term $\left(\sigma_{\text {iso }}\right)$.

A detailed overview of the effects of the basis set and the Hamiltonian on the charge distribution can be found in references. The charge density profiles in this study has been extracted from firstprinciples calculation through an averaging process as described in reference. The interaction energy for capacitor was calculated in all items according to the equation as follows: $\Delta E_{S}(\mathrm{eV})=$ $E_{\text {systems }}-\left\{E_{S W C N T S}+\left(\sum_{i=1}^{n}(\right.\right.$ antibiotics $\left.)\right\}$ Where the " $\Delta E_{S}$ " is the stability energy. 


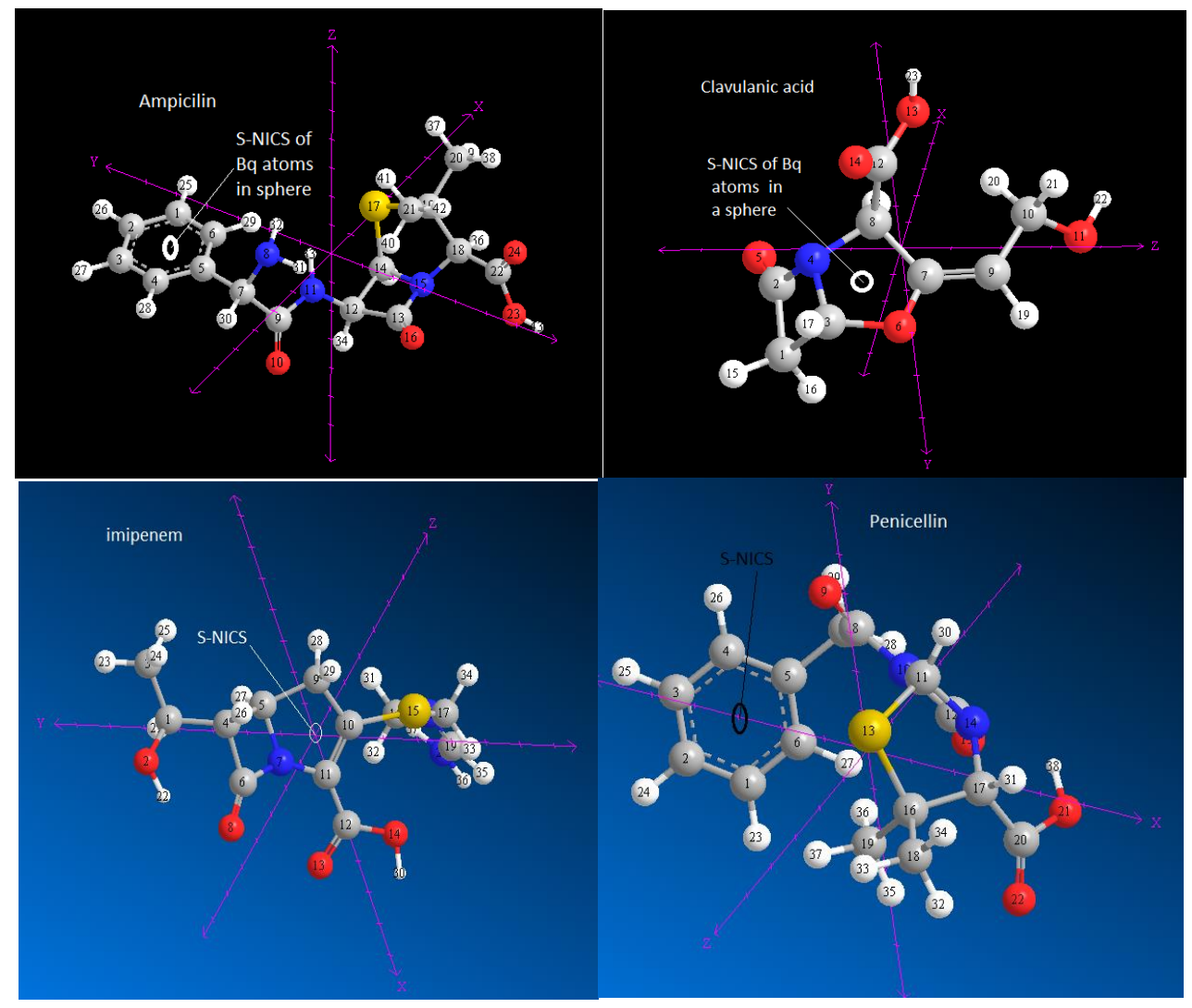

Figure 1. Clavulanic acid, Ampicillin, imipenem, and Penicillin G structures

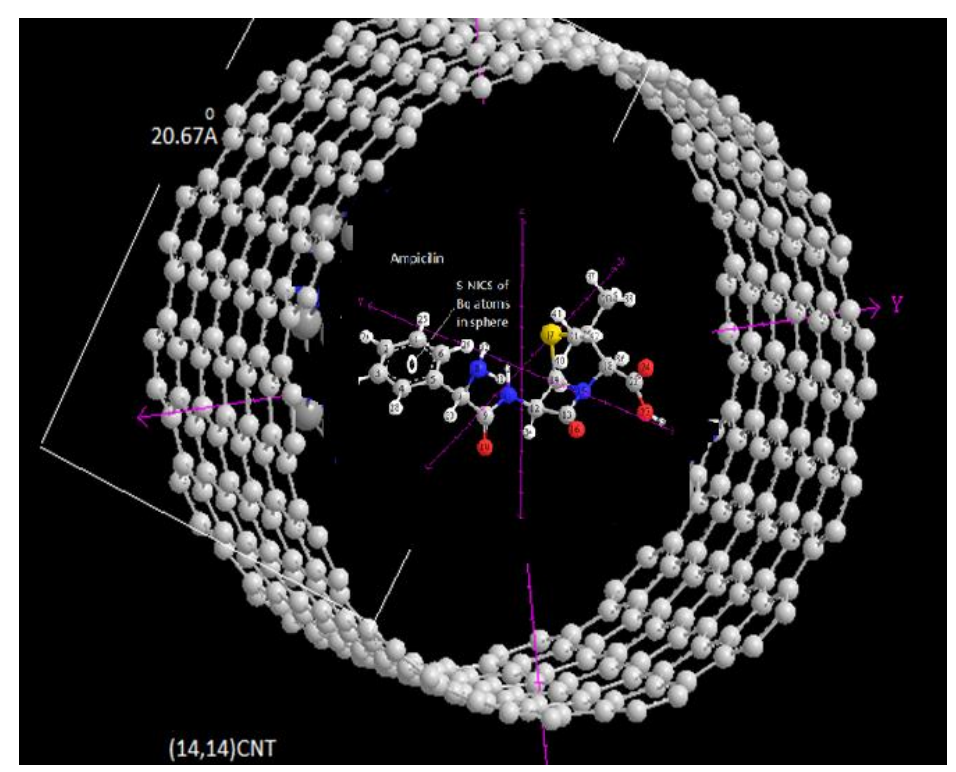

Figure 2. Ampicillin inside $(14,14) \mathrm{CNT}$ as a nanotube delivering

Nexo Revista Científica / Vol. 33, No. 01, pp. 121-136 / Junio 2020 


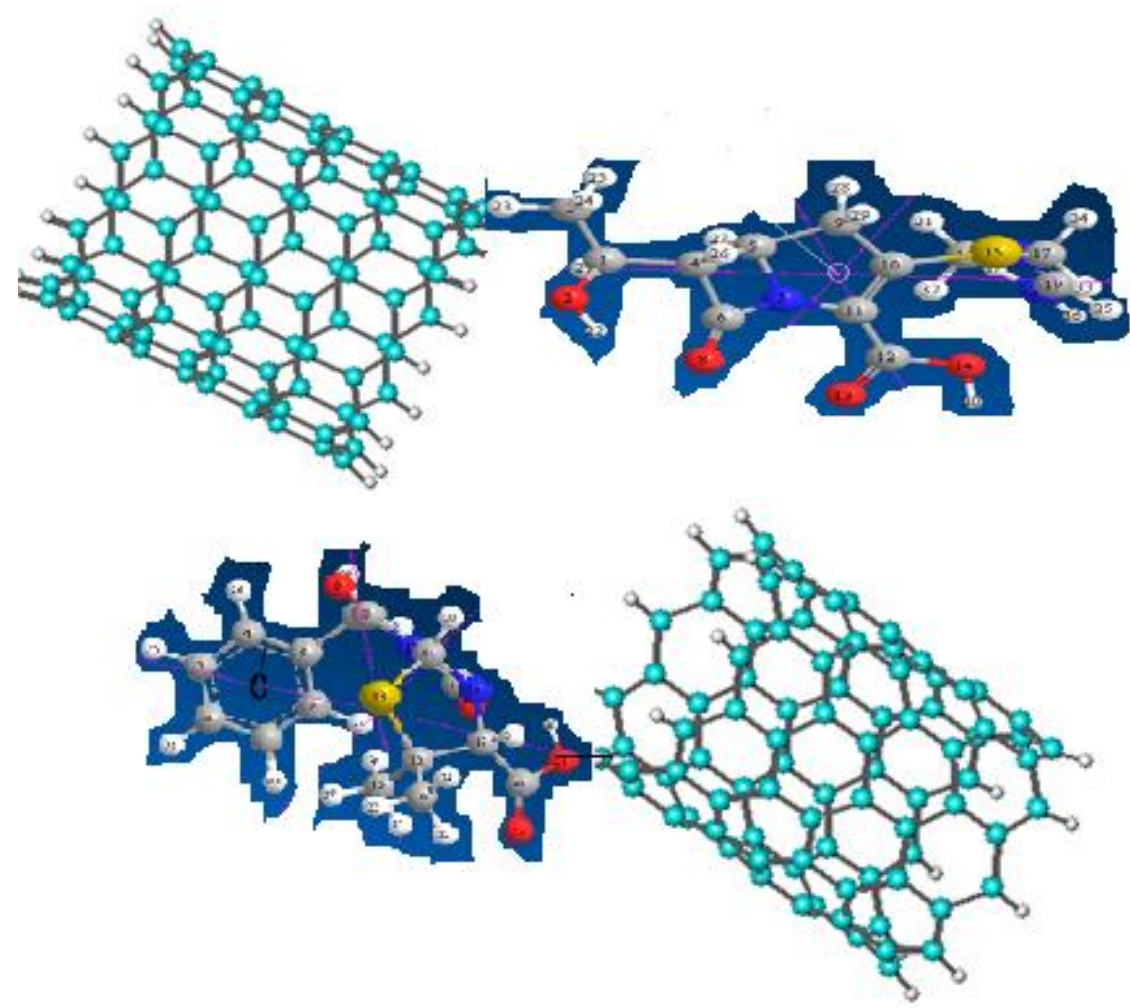

Figure 3. Imipenem and penicillin bonded to nanotube carbon

The quantum mechanics "(QM)" calculations were carried out with the HyperChem 8.0 program. This study mainly focuses on the electron density Ampicillin, Clavulanic acid, Imipenem, Penicillin G and Ticarcillin in viewpoint of "S-NICS" method. The models and situation of molecular structures and binding interaction are shown in figs1- 5. As it is indicated in tables 1-3, the NMR parameters including isotropy, anisotropy, asymmetry, span and S-NICS value have been simulated. According to the mentioned equations the largest electron localization is located on atoms which are bonded to nanotubes where the electron motion is more likely to be confined within that region. If electrons are completely localized in those atoms, they can be distinguished from the ones outside. As shown the large density is close to the bonded atoms. The regions with large electron localization need to have large magnitudes of Fermi-hole integration which would lead those atoms towards superparamagnetic. The fermi hole is a six-dimension function and as a result, it is difficult to be studied visually. Based those equations, Becke and Edgecombe noted (Becke, 1990) that the Fermi hole is a spherical average of the spin which is in good agreement with our results in tables and Figs.

\section{CONCLUSION}

A number of computational chemistry studies carried out to understand the conformational preferences that may be attributed to stereo electronic effects. These results show the minimized structure of mentioned antibiotics with SWCNTs and SWBNNTs, calculated potential energy for important dihedral angles, and the effect of temperature on geometry of optimized structure(Le, 2020, 2019). NMR by GIAO approximation, have been applied for determination of the situation in antibiotics - SWCNT and shifting. This model provides an atomistic analysis of the antibiotics-

Nexo Revista Científica / Vol. 33, No. 01, pp. 121-136 / Junio 2020 
SWCNT strategy and its implications for further investigations of drugs. Once a compound that fulfills all of these requirements has been identified, it will begin the process of drug development prior to clinical trials. Modern drug discovery involves the identification of screening hits, medicinal chemistry and optimization of those hits to increase some properties. One or more of these steps may involve computer-aided drug design. The fascinating result of the theoretical analysis of "antibiotics- S-NICS" methods was the stable model for "drug delivery". The observed behavior must reflect intrinsic properties of the mechanism of its structure and provides useful constraints for the development of mechanistic models (Pham, 2019,2020).

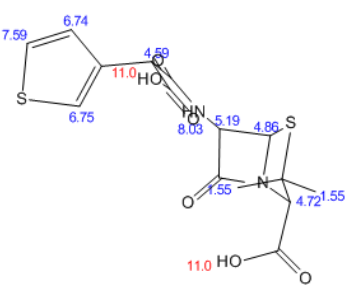

Estimation quality is indicated by color: good, medium, rough

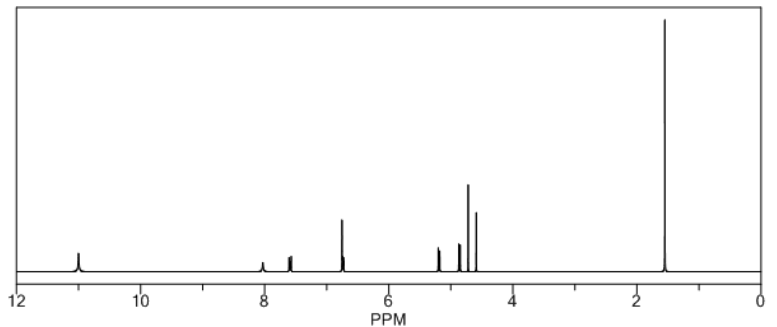

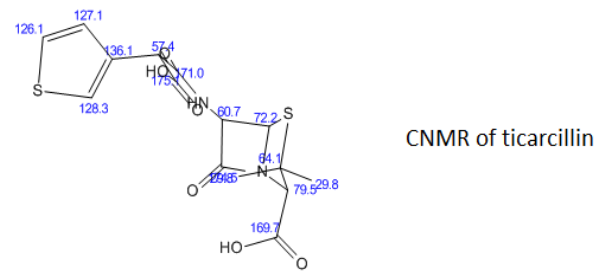

Estimation quality is indicated by color: good, medium, rough

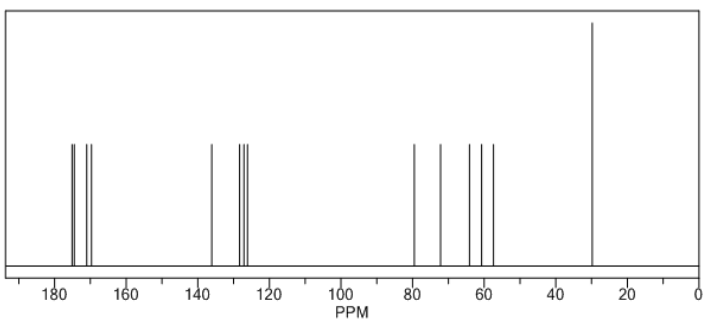

Figure 4. Proton \& Carbon NMR of Ticarcillin

ChemNMR ${ }^{1} \mathrm{H}$ Estimation

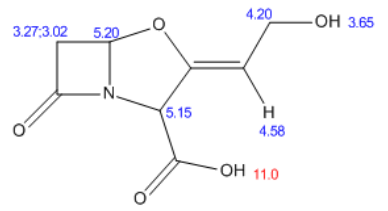

Clavulanic acid
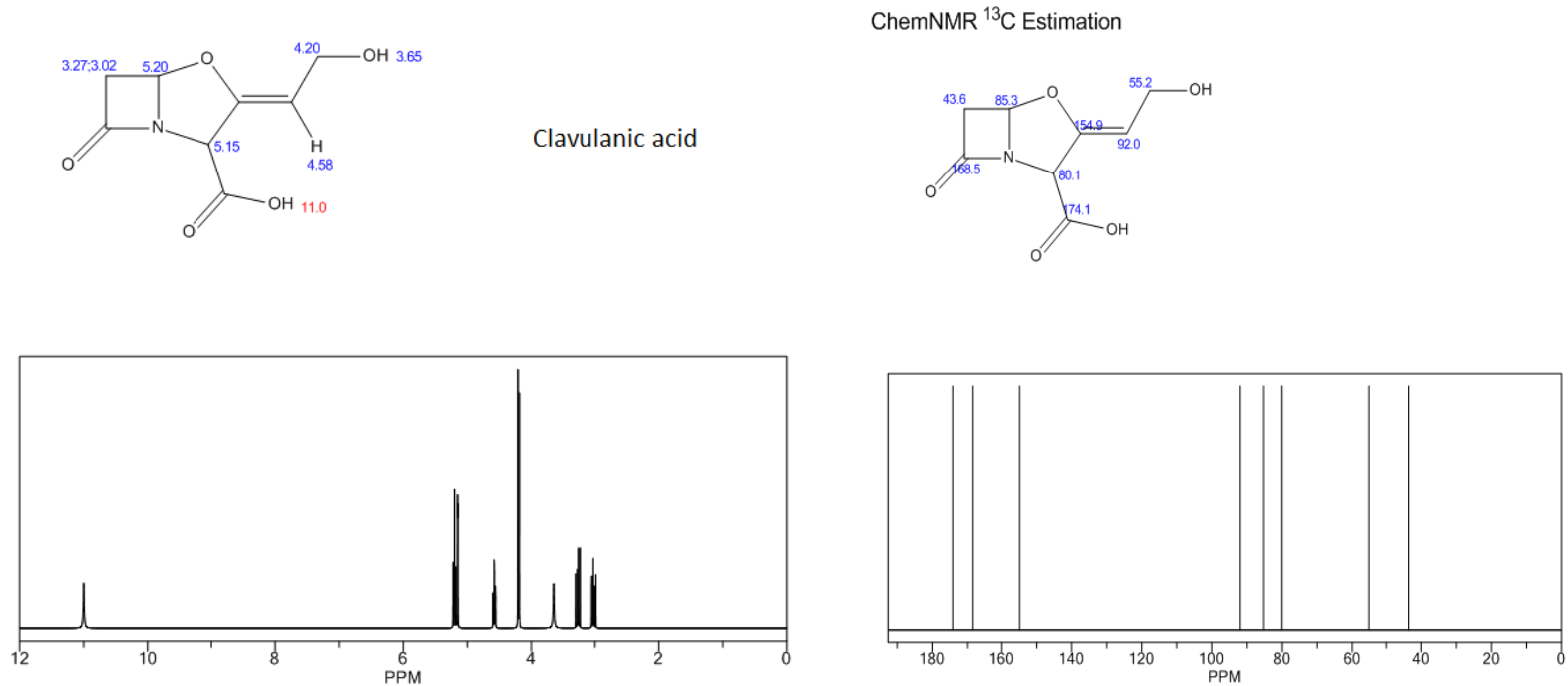

Figure 5. Proton \& Carbon NMR of Clavuanic acid 
Table1: Charge (ESP), isotropy, anisotropy, span and aromaticity of Ampicillin-CNTs in gas phase and solvent

\begin{tabular}{|c|c|c|c|c|c|c|c|c|c|c|c|c|c|}
\hline \multicolumn{7}{|c|}{ Ampicillin gas phase } & \multicolumn{7}{|c|}{ Ampicillin in water } \\
\hline Atom & Charge & бiso & бaniso & $\eta$ & $\Delta \delta$ & $\Omega$ & atom & charge & бiso & бaniso & $\eta$ & $\Delta \delta$ & $\mathbf{\Omega}$ \\
\hline $3 \mathrm{C}$ & 0.243 & 120.5 & 35.8 & 8.60 & 26.9 & -15.387 & $3 \mathrm{C}$ & 0.242 & 120.2 & 36.1 & 0.28 & 36.13 & 24.09 \\
\hline $5 \mathrm{C}$ & -0.678 & 248.3 & 47.2 & 8.6 & 59.0 & -27.5 & $5 \mathrm{C}$ & -0.69 & 245.2 & 50.4 & 0.58 & 50.4 & 33.6 \\
\hline $17 \mathrm{O}$ & -0.36 & 144.6 & 28.2 & 6.9 & 23.9 & -17.3 & 170 & 0.104 & 29.7 & 7.9 & 0.85 & -8.54 & -5.6 \\
\hline 220 & -0.46 & 166.9 & 24.6 & 8.9 & 29.9 & -13.3 & 220 & -0.24 & 110.6 & 40.4 & 0.36 & -59.0 & -39.3 \\
\hline 210 & -0.50 & 294.0 & 72.4 & 8.45 & 52.9 & -31.3 & 210 & -0.46 & 167.2 & 24.3 & 0.6 & 24.3 & 16.2 \\
\hline $15 \mathrm{~S}$ & 0.413 & 28.6 & 14.67 & 0.76 & -16.65 & -11.10 & $15 \mathrm{~S}$ & 0.415 & 28.4 & 14.8 & 0.77 & -16.7 & -11.17 \\
\hline 110 & 0.12 & 27.8 & 9.051 & 0.66 & 9.05 & 6.034 & 110 & 0.140 & 29.9 & 7.5 & 0.70 & -8.82 & -5.8 \\
\hline $4 \mathrm{C}$ & 0.13 & 29.4 & 6.03 & 0.52 & 6.03 & 4.02 & $4 \mathrm{C}$ & -0.25 & 160.8 & 12.0 & 0.97 & -12.13 & -8.089 \\
\hline $3 \mathrm{C}$ & -0.283 & 152.1 & 26.84 & 9.63 & 30.85 & -12.76 & $3 \mathrm{C}$ & 0.132 & 29.4 & 6.25 & 0.48 & 6.25 & 4.16 \\
\hline $12 \mathrm{~N}$ & -0.09 & 148.4 & 25.1 & 8.98 & 29.9 & -13.3 & $12 \mathrm{~N}$ & -0.09 & 148.8 & 24.9 & 0.58 & 24.9 & 16.6 \\
\hline $11 \mathrm{C}$ & 0.322 & 65.43 & 93.16 & 0.25 & 93.16 & 62.11 & $11 \mathrm{C}$ & -0.24 & 157.5 & 11.47 & 0.72 & -13.30 & -8.86 \\
\hline $8 \mathrm{C}$ & -0.258 & 160.5 & 12.67 & 13.0 & 37.50 & -8.33 & $8 \mathrm{C}$ & -0.52 & 244.2 & 98.4 & 0.54 & -127.4 & -84.9 \\
\hline $6 \mathrm{~N}$ & 0.006 & 121.9 & 34.8 & 9.7 & 29.5 & -13.6 & $6 \mathrm{~N}$ & -0.284 & 152.2 & 26.40 & 0.43 & 26.40 & 17.60 \\
\hline $18 \mathrm{~N}$ & 0.237 & 67.88 & 96.88 & 0.44 & 96.88 & 64.59 & $18 \mathrm{~N}$ & -0.50 & 293.7 & 72.9 & 0.33 & 72.9 & 48.6 \\
\hline $19 \mathrm{C}$ & -0.45 & 168.5 & 22.9 & 8.6 & 29.7 & -13.4 & $19 \mathrm{C}$ & -0.45 & 168.4 & 22.7 & 0.78 & 22.7 & 15.1 \\
\hline $14 \mathrm{C}$ & -0.19 & 130.3 & 65.7 & 5.9 & 9.53 & -26.9 & $14 \mathrm{C}$ & -0.19 & 129.9 & 67.5 & 0.20 & 67.5 & 45.0 \\
\hline $13 \mathrm{C}$ & 0.130 & 76.92 & 141.3 & 0.23 & 141.3 & 94.21 & $13 \mathrm{C}$ & 0.335 & 62.2 & 95.9 & 0.25 & 95.99 & 63.99 \\
\hline $25 \mathrm{H}$ & 0.12 & 25.4 & 12.86 & 0.59 & 12.86 & 8.5 & $25 \mathrm{H}$ & 0.13 & 25.7 & 13.3 & 0.59 & 13.3 & 8.87 \\
\hline $24 \mathrm{H}$ & 0.13 & 29.7 & 10.1 & 0.53 & 10.15 & 6.7 & $24 \mathrm{H}$ & 0.140 & 29.7 & 10.2 & 0.53 & 10.28 & 6.85 \\
\hline $23 \mathrm{H}$ & 0.077 & 78.31 & 140.6 & 0.35 & 140.6 & 93.76 & $23 \mathrm{H}$ & -0.328 & 89.87 & 107.9 & 0.77 & 107.93 & 71.95 \\
\hline $22 \mathrm{H}$ & 0.10 & 29.8 & 8.01 & 0.90 & -8.4 & -5.61 & $22 \mathrm{H}$ & 0.154 & 73.57 & 132.9 & 0.22 & 132.9 & 88.61 \\
\hline $29 \mathrm{H}$ & 0.138 & 29.97 & 7.36 & 0.68 & -8.72 & -5.81 & $29 \mathrm{H}$ & 0.14 & 30.2 & 9.33 & 0.40 & 9.33 & 6.22 \\
\hline $31 \mathrm{H}$ & -0.3116 & 85.40 & 114.26 & 0.83 & 114.26 & 76.17 & $31 \mathrm{H}$ & 0.13 & 27.8 & 9.17 & 0.65 & 9.17 & 6.11 \\
\hline $34 \mathrm{H}$ & 0.14 & 30.2 & 9.46 & 0.40 & 9.46 & 6.31 & $34 \mathrm{H}$ & 0.074 & 75.88 & 144.3 & 0.34 & 144.3 & 96.22 \\
\hline $37 \mathrm{H}$ & 0.14 & 30.0 & 7.1146 & 0.80 & -7.88 & -5.25 & $37 \mathrm{H}$ & 0.146 & 30.00 & 6.87 & 0.82 & -7.52 & -5.01 \\
\hline $23 \mathrm{H}$ & 0.1803 & 73.56 & 153.2 & 0.49 & 153.23 & 102.1 & $23 \mathrm{H}$ & 0.187 & 74.61 & 151.7 & 0.47 & 151.7 & 101.1 \\
\hline $36 \mathrm{H}$ & 0.134 & 28.3 & 9.349 & 0.59 & 9.34 & 6.23 & $36 \mathrm{H}$ & 0.134 & 28.3 & 9.29 & 0.58 & 9.29 & 6.19 \\
\hline
\end{tabular}

Table2: Charge (ESP), isotropy, anisotropy, span and aromaticity of Clavulanic acid-CNTs in gas phase and solvent media

\begin{tabular}{|c|c|c|c|c|c|c|c|c|c|c|c|c|c|}
\hline \multicolumn{7}{|c|}{ Clavulanic acid in gas phase } & \multicolumn{7}{|c|}{ Clavulanic acid in water } \\
\hline atom & $\begin{array}{c}\text { charg } \\
\text { e }\end{array}$ & riso & oaniso & $\eta$ & $\Delta \boldsymbol{\delta}$ & $\boldsymbol{\Omega}$ & atom & charge & бiso & oaniso & $\eta$ & $\Delta \boldsymbol{\delta}$ & $\mathbf{\Omega}$ \\
\hline $\mathbf{C}(\mathbf{5})$ & -0.4 & 167.0 & 24.5 & 0.1 & -120.6 & 113.7 & $\mathbf{C}(\mathbf{5})$ & -0.24 & 157.4 & 11.6 & 0.0 & -113.5 & 109.0 \\
\hline $\mathbf{C}(3)$ & -0.25 & 160.5 & 12.4 & 0.0 & -112.1 & 108.1 & $\mathbf{C}(\mathbf{3})$ & 0.24 & 66.7 & 98.4 & 0.4 & 98.4 & 65.6 \\
\hline $\mathbf{O}(\mathbf{1})$ & -0.2 & 157.6 & 11.6 & 0.0 & -113.7 & 109.5 & $\mathbf{O ( 1 )}$ & -0.32 & 88.9 & 110.4 & 0.7 & 110.4 & 73.63 \\
\hline $\mathbf{O}(14)$ & -0.50 & 293.83 & 71.96 & 0.2 & -247.9 & 231.8 & $\mathbf{O}(14)$ & 0.16 & 76.6 & 129.4 & 0.2 & 129.4 & 86.3 \\
\hline $\mathbf{O}(12)$ & -0.19 & 130.4 & 65.3 & 0.4 & -140.0 & 126.6 & $\mathbf{O}(12)$ & 0.34 & 63.4 & 94.8 & 0.2 & 94.89 & 63.2 \\
\hline $\mathbf{O}(16)$ & 0.005 & 121.8 & 35.1 & 0.2 & -120.6 & 113.7 & $\mathbf{O}(\mathbf{1 6})$ & 0.183 & 74.96 & 151.8 & 0.4 & 151.8 & 101.2 \\
\hline $\mathbf{C}(\mathbf{8})$ & 0.32 & 65.27 & 93.7 & 0.2 & 93.78 & 62.5 & $\mathrm{C}(\mathbf{8})$ & -0.52 & 242.1 & 87.2 & 0.1 & -234.0 & 189.3 \\
\hline
\end{tabular}


Maryam Derakhshandeh and Majid Monajjemi

\begin{tabular}{|c|c|c|c|c|c|c|c|c|c|c|c|c|c|}
\hline $\mathrm{C}(17)$ & 0.23 & 67.9 & 97.0 & 0.4 & 97.0 & 64.6 & $\mathrm{C}(17)$ & 0.14 & 29.9 & 7.41 & 0.6 & -8.7 & -5.81 \\
\hline $\mathbf{C}(7)$ & -0.44 & 141.1 & 29.9 & 0.1 & -125.7 & 117.1 & C(7) & -0.28 & 152.1 & 26.4 & 0.2 & -118.8 & 112.5 \\
\hline $\mathbf{C}(9)$ & -0.45 & 168.3 & 22.9 & 0.1 & -120.7 & 113.8 & $\mathbf{C}(\mathbf{9})$ & 0.07 & 76.4 & 144.4 & 0.3 & 144.4 & 96.3 \\
\hline $\mathbf{C}(\mathbf{1 1})$ & -0.67 & 248.3 & 46.93 & 0.1 & -240.6 & 227.0 & $\mathbf{C}(\mathbf{1 1})$ & -0.67 & 247.1 & 49.33 & 0.1 & -241.2 & -27.4 \\
\hline $\mathrm{C}(\mathbf{1 8})$ & 0.13 & 78.2 & 139.2 & 0.2 & 139.2 & 92.8 & $\mathrm{C}(\mathbf{1 8})$ & -0.5 & 293.6 & 72.8 & 0.2 & -248.5 & 232.3 \\
\hline H(19) & -0.53 & 250.2 & 65.4 & 0.0 & -219.2 & 179.4 & $\mathbf{H}(\mathbf{1 9})$ & -0.25 & 160.6 & 12.2 & 0.0 & -112.5 & 108.3 \\
\hline $\mathbf{H}(25)$ & 0.1 & 29.8 & 8.0 & 0.9 & -8.4 & 5.3 & $\mathbf{H}(\mathbf{2 5})$ & 0.10 & 29.7 & 7.9 & 0.8 & -8.4 & -5.6 \\
\hline $\mathbf{H}(26)$ & 0.14 & 30.2 & 9.4 & 0.4 & 9.45 & 6.30 & $\mathbf{H}(26)$ & 0.14 & 30.2 & 9.43 & 0.4 & 9.4 & 6.2 \\
\hline H(29) & 0.24 & 120.5 & 36.0 & 0.2 & -123.4 & 115.6 & H(29) & -0.46 & 167.2 & 24.5 & 0.1 & -120.3 & 113.5 \\
\hline $\mathbf{H}(27)$ & -0.09 & 148.6 & 25.2 & 0.1 & -119.0 & 113.1 & $\mathbf{H}(27)$ & -0.45 & 168.4 & 22.8 & 0.1 & -120.4 & 113.6 \\
\hline $\mathbf{H}(\mathbf{3 3})$ & -0.28 & 152.07 & 26.29 & 0.2 & -118.7 & 112.5 & $\mathbf{H}(\mathbf{3 3})$ & -0.19 & 130.5 & 65.3 & 0.4 & -140.1 & 126.7 \\
\hline $\mathbf{H}(35)$ & 0.12 & 25.5 & 12.2 & 0.6 & 12.2 & 8.1 & $\mathbf{H}(\mathbf{3 5})$ & -0.094 & 148.8 & 25.240 & 0.1 & -119.6 & 113.1 \\
\hline $\mathbf{H}(40)$ & 73.5 & 153.0 & 0.4 & 153 & 102.0 & 6.70 & $\mathbf{H}(\mathbf{4 0})$ & 0.13 & 25.8 & 12.4 & 0.6 & 12.48 & 8.3 \\
\hline
\end{tabular}

Table3: Charge (ESP), isotropy, anisotropy, span and aromaticity of Clavulanic acid-CNTs in gas phase and solvent media

\begin{tabular}{|c|c|c|c|c|c|c|c|c|c|c|c|c|c|}
\hline \multicolumn{7}{|c|}{ Imipenem in gas phase } & \multicolumn{7}{|c|}{ Imipenem in water } \\
\hline atom & charge & бiso & oaniso & $\eta$ & $\Delta \delta$ & $\boldsymbol{\Omega}$ & atom & charge & бiso & oaniso & $\eta$ & $\Delta \delta$ & $\boldsymbol{\Omega}$ \\
\hline $\mathrm{C}(6)$ & -0.25 & 160.4 & 12.8 & 0.9 & 112. & 8.5 & $\mathrm{C}(6)$ & -0.25 & 160.3 & 12.7 & 0.0 & 112. & 108. \\
\hline $\mathrm{C}(3)$ & 0.00 & 121.6 & 34.4 & 0.1 & 134. & 22.9 & $\mathrm{C}(3)$ & -0.6 & 248.6 & 46.9 & 0.1 & 240. & 226. \\
\hline $\mathbf{O}(7)$ & -0.32 & 92.04 & 125.2 & 0.7 & 125. & 83.4 & $O(7)$ & -0.32 & 90.6 & 138.8 & 0.6 & 138. & 92.5 \\
\hline $\mathbf{O}(11)$ & 0.07 & 79.2 & 131.9 & 0.4 & 131. & 87.9 & $\mathbf{O}(11)$ & -0.2 & 152.1 & 26.1 & 0.3 & 126. & 17.4 \\
\hline$O(15)$ & -0.01 & 78.9 & 128.3 & 0.3 & 128. & 85.5 & $O(15)$ & 0.32 & 64.9 & 93.1 & 0.2 & 93.1 & 62.0 \\
\hline $\mathbf{P}(\mathbf{1 2})$ & 0.07 & 80.3 & 138.7 & 0.3 & 138. & 92.5 & $\mathbf{P}(12)$ & 0.24 & 120.1 & 36.12 & 0.2 & 123. & 115. \\
\hline $\mathbf{O}(8)$ & -0.09 & 148.6 & 25.3 & 0.5 & 125. & 16.9 & $\mathbf{O}(8)$ & 0.18 & 73.4 & 154.9 & 0.4 & 154. & 103. \\
\hline C(17) & 0.006 & 121.9 & 35.2 & 0.2 & 120. & 113. & $\mathbf{C}(17)$ & -0.50 & 293.0 & 74.2 & 0.2 & 249. & 232. \\
\hline $\mathrm{C}(19)$ & 0.23 & 67.42 & 98.40 & 0.4 & 98.4 & 65.6 & $\mathrm{C}(19)$ & -0.09 & 148.6 & 25.3 & 0.1 & 119. & 113. \\
\hline C(3) & 0.24 & 120.5 & 36.1 & 0.3 & 136. & 24.0 & $\mathbf{C}(3)$ & 0.07 & 76.9 & 143.0 & 0.3 & 143. & 95. \\
\hline $\mathbf{C}(\mathbf{1 8})$ & -0.6 & 247.1 & 47.3 & 0.6 & 247. & 31.5 & $\mathrm{C}(18)$ & -0.4 & 168.2 & 23.2 & 0.8 & 123. & 15.5 \\
\hline $\mathbf{C}(21)$ & -0.5 & 252.0 & 81.2 & 0.4 & 231. & 54.1 & $\mathbf{C}(21)$ & 0.18 & 74.8 & 153.2 & 0.5 & 153. & 102. \\
\hline $\mathbf{C}(20)$ & -0.28 & 152.3 & 25.6 & 0.1 & 117. & 111. & $\mathbf{C}(20)$ & -0.5 & 253.3 & 84.1 & 0.1 & 221. & 181. \\
\hline $\mathbf{C}(13)$ & 0.44 & 81.03 & 33.3 & 0.8 & 33.3 & 22.2 & $\mathbf{C}(13)$ & -0.45 & 168.4 & 22.9 & 0.1 & 120. & -13 \\
\hline $\mathbf{C}(24)$ & -0.18 & 130.6 & 63.9 & 0.2 & 163. & 42.6 & $\mathrm{C}(24)$ & -0.19 & 130.4 & 65.31 & 0.4 & 139. & 126. \\
\hline $\mathbf{C}(27)$ & -0.46 & 167.0 & 24.7 & 0.7 & 124. & 16.5 & $\mathbf{C}(27)$ & -0.46 & 167.2 & 24.5 & 0.1 & 120. & 113. \\
\hline $\mathbf{H}(\mathbf{3 0})$ & 0.13 & 29.7 & 10.0 & 0.5 & 10.0 & 6.6 & $\mathbf{H}(\mathbf{3 0})$ & 0.13 & 29.7 & 10.0 & 0.5 & 10.0 & 6.70 \\
\hline $\mathbf{H}(35)$ & 0.13 & 29.9 & 7.24 & 0.6 & -8.62 & -5.75 & $\mathbf{H}(35)$ & 0.13 & 29.9 & 7.31 & 0.6 & 8.71 & 5.80 \\
\hline
\end{tabular}

Nexo Revista Científica / Vol. 33, No. 01, pp. 121-136 / Junio 2020 
Maryam Derakhshandeh and Majid Monajjemi

\begin{tabular}{|c|c|c|c|c|c|c|c|c|c|c|c|c|c|}
\hline H(39) & 0.12 & 27.8 & 9.01 & 0.6 & 9.01 & 6.0 & H(39) & 0.003 & 107.3 & 83.1 & 0.4 & 83.1 & 55.4 \\
\hline H(41) & 0.12 & 26.1 & 11.1 & 0.6 & 11.1 & 7.4 & $\mathbf{H}(41)$ & 0.14 & 25.2 & 12.3 & 0.7 & 12.3 & 8.2 \\
\hline $\mathbf{H}(44)$ & 0.1 & 29.7 & 7.9 & 0.9 & -8.1 & -5.4 & $\mathbf{H}(\mathbf{4 4 )}$ & 0.1 & 29.7 & 8.06 & 0.9 & -8.3 & -5.5 \\
\hline H(47) & 0.14 & 30.1 & 9.4 & 0.4 & 9.46 & 6.31 & $\mathbf{H}(47)$ & 0.14 & 30.2 & 9.49 & 0.4 & 9.49 & 6.3 \\
\hline H(48) & 0.14 & 29.9 & 7.18 & 0.8 & -7.9 & -5.31 & $\mathbf{H}(48)$ & 0.14 & 29.9 & 7.16 & 0.7 & -8.0 & -5.3 \\
\hline $\mathbf{H}(\mathbf{5 0})$ & 0.13 & 28.3 & 9.5 & 0.6 & 9.50 & 6.33 & $\mathbf{H}(\mathbf{5 0})$ & 0.1 & 29.7 & 7.9 & 0.9 & -8.1 & -5.4 \\
\hline $\mathbf{H}(\mathbf{3 3})$ & 0.41 & 28.6 & 14.4 & 0.7 & $\begin{array}{l}-16.3 \\
\end{array}$ & -10.9 & $\mathbf{H}(\mathbf{3 3})$ & 0.41 & 28.5 & 14.5 & 0.7 & 14.5 & 11.0 \\
\hline
\end{tabular}

\section{REFERENCES}

Boxall, A. B. A., Fogg, L. A., Blackwell, P. A., Kay, P., Pemberton, E. J., Croxford, A. (2004) "Veterinary medicines in the environment," Reviews of Environmental Contamination and Toxicology, 180, 1-91.

Berlin, H. W. (1978), Spiess, In NMR Basic Principles and Progress; P. Diehl, E. Fluck, R. Kosfeld, Eds.; Springer Verlag, Berlin, Vol. 15

Bader, R.F.W., (1990) atoms in Molecule: A quantum Theory (Oxford Univ. press, Oxford.

Becke and Edgecombe (1990), J. Chem. Phys., 92, 5397

Beer, P.D., Gale,P.A., (2001), Anion Recognition and Sensing: The State of the Art and Future Perspectives Angew. Chem. Int. Ed. 40, 486-516.

Dang, D. M. T., d Monajjemi, M., Mollaamin, F., Dang, C.M., (2020) Simulation of droplet ejection based on electromechanical parameters \& chemical condition for controlling inkjet printing devices Biointerface Research in Applied chemistry , Volume 10, Issue 3, 5361 - 5368, https://doi.org/10.33263/BRIAC103.361368

EL-Kosasy A, Salem M, EL-Bardicy M, Abdelrahman M. (2009) Membrane Electrodes for the Determination of Pyridostigmine Bromide. J. AOAC Int. 92 :1631 -1638

Genc, Y., Ozkanca, R., Bekdemir, Y. (2008), Ann Clin Microbiol Antimicrob, 7: 7-17.

Burkhart, C.G. (2008), Open Dermatol, J 2008; 2: 36-43.

Kumar, P., Shim, Y., (2009) A novel cobalt (II)-selective potentiometric sensor based on p-(4-nbutylphenylazo) calix[4]arene. Talanta 2009; 77: 1057-1062

Kuruoglu, D., Canel, E., Memon, S., Yildiz, M., Kılı,c,E.,(2003) Anal. Sci. 19, 217-221

Kim D, Wang L, Beconi M et al. "(2R)-4-oxo-4-[3-(trifluoromethyl)-5, 6- potent, orally active dipeptidyl peptidase IV inhibitor for the treatment of type 2 diabetes". J. Med.Chem. 2005; 48: $141-151$.

Lee, V.S., , Russian Journal of Physical Chemistry A, (2009) Investigation of single wall carbon nanotubes electrical properties and normal mode analysis: Dielectric effects , 83, 13, 2288-2296 
Maryam Derakhshandeh and Majid Monajjemi

Lu, T., Chen. F., (2012) Multiwfn: A Multifunctional Wavefunction Analyzer, J. Comp. Chem. (33)580592

Le, C.M.T., Mollaamin, F., Dang, D.M.T., Monajjemi, M., Dang, C.M., (2019), Realistic simulation of the polymers in inkjet process: the investigation of physical phenomena in the ejection of a droplet, Biointerface Research in Applied chemistry, Volume 9, Issue 3, 3949 - 3955, https://doi.org/10.33263/BRIAC93.949955

Li, J. J., Anderson, D., Burton, E. G., Cogburn, J. N., Collins, J. T., Garland, D. J., Gregory, H. Huang, S. A.C., Isakson, P.C., Koboldt, C.M., Logusch, E.W., Norton, M.B., Perkins, W.E., Reinhard, E.J., Seibert, K., Veenhuizem, A.W., Zang, Y., Reitz, D.W., (1995) J. Med. Chem., 38, 4570.

Le, C.M.T., Monajjemi, M., Pham, T.T., Mollaamin, F., Dang, C.M., (2020) Diffusion \& concentration effect of $\mathrm{Li} / \mathrm{Li}+$ to the efficiency of LIBs, Biointerface Research in Applied chemistry, Volume 10, Issue 2, 5076 - 5084, https://doi.org/10.33263/BRIAC102.076084

Le, C.M.T., Monajjemi, M., Pham, T.T., Mollaamin, F., Dang, C.M., (2019), Simulation \& modelling of dilute solutions in drop-on-demand inkjet printing: a review, Biointerface Research in Applied chemistry, Volume 9, Issue 6, 4474 - 4484, https://doi.org/10.33263/BRIAC96.474484

McMahon,G., Malley,S.O., Nolan.K., Diamond,D., (2003) Arkivoc Important calixarene derivatives - their synthesis and applications 23-31 DOI: http://dx.doi.org/10.3998/ark. 5550190.0004.704.

Monajjemi, M., (2019) Molecular biology's symphony orchestra from DNA to ribosome: a sonification from gene to protein, Biointerface Research in Applied chemistry, Volume 10, Issue 4, 5679 - 5688. https://doi.org/10.33263/BRIAC104.679688

Monajjemi, M., Mollaamin, F., Shojaei, S., (2020) An overview on Coronaviruses family from past to Covid-19: introduce some inhibitors as antiviruses from Gillan's plants, Biointerface Research in Applied chemistry, Volume 10, Issue 3, 5575 - 5585. https://doi.org/10.33263/BRIAC103.575585

Monajjemi, M., Shahriari, S., Mollaamin, F., (2020) Evaluation of Coronavirus Families \& Covid-19 Proteins: Molecular Modeling Study, Biointerface Research in Applied chemistry, Volume 10, Issue 5, 6039 - 6057. https://doi.org/10.33263/BRIAC105.60396057

Monajjemi, M., Naghsh, F., Mollaamin, F., (2020) Bio-Lipid Nano Capacitors: Resonance with Helical Myeline Proteins, Biointerface Research in Applied chemistry, Volume 10, Issue 6, 6695 - 6705, https://doi.org/10.33263/BRIAC106.66956705

Monajjemi,M., Mollaamin, F., (2020) Bio-capacitor consist of insulated myelin-sheath and uninsulated node of Ranvier: a bionano-antenna, Biointerface Research in Applied chemistry, Volume 10, Issue 1, 4956 - 4965, https://doi.org/10.33263/BRIAC101.956965

Monajjemi, M., (2019), Artificial intelligence \& self-consistent sonification method for converting DNA sequence to music, Biointerface Research in Applied chemistry, Volume 9, Issue 6, 4494 - 4501, https://doi.org/10.33263/BRIAC96.494501

Mollaamin, F., Pham, T.T., Dang , D.M.T., Monajjemi, M., Dang, C.M., (2019) Modelling and Controlling of ion transport rate efficiency in Proton exchange membrane (PEMFC), alkaline (AFC), direct methanol (DMFC), phosphoric acid (PAFC), direct forming acid(DFAFC) and direct carbon (DCFC) fuel cells,

Nexo Revista Científica / Vol. 33, No. 01, pp. 121-136 / Junio 2020 
Maryam Derakhshandeh and Majid Monajjemi

Biointerface Research in Applied chemistry , Volume 9, Issue 4, 4050 - 4059, https://doi.org/10.33263/BRIAC94.050059

Monajjemi, M., (2019) ,C-NMR sonification of human insulin: a method for conversion of amino-acid sequences to music notes, Biointerface Research in Applied chemistry, Volume 9, Issue 4, 4077 https://doi.org/10.33263/BRIAC94.077084

Monajjemi, M., (2019), Molecular vibration of dopamine neurotransmitter: a relation between its normal modes and harmonic notes, Biointerface Research in Applied chemistry, Volume 9, Issue 3, 3956 - 3962, https://doi.org/10.33263/BRIAC93.956962

Monajjemi, M., Lee, V.S., Khaleghian, M., Honarparvar, B., Mollaamin, F. (2010). Theoretical Description of Electromagnetic Nonbonded Interactions of Radical, Cationic, and Anionic NH2BHNBHNH2 Inside of the B18N18 Nanoring. J. Phys. Chem C, 114, 15315. https://doi.org/10.1021/jp104274z

Monajjemi, M., Mohammadian, N.T. (2015). S-NICS: An Aromaticity Criterion for Nano Molecules. J. Comput. Theor. Nanosci, 12(11), 4895-4914. https://doi.org/10.1166/jctn.2015.4458

Monajjemi, M., Robert Wayne, Jr., Boggs, J.E. (2014). NMR contour maps as a new parameter of carboxyl's $\mathrm{OH}$ groups in amino acids recognition: A reason of tRNA-amino acid conjugation. Chemical Physics, 433(3), $\quad 1 \quad-11 . \quad$ https://doi.org/10.1016/j.chemphys.2014.01.017

Monajjemi, M. (2015). Cell membrane causes the lipid bilayers to behave as variable capacitors: A resonance with selfinduction of helical proteins. Biophysical Chemistry, 207, 114-127. https://doi.org/10.1016/j.bpc.2015.10.003

Monajjemi, M. (2015). Non-covalent attraction of B2N(-,0) and repulsion of $\mathrm{B} 2 \mathrm{~N}(+)$ in the $\mathrm{BnNn}$ ring: a quantum rotatory due to an external field. Theor. Chem. Ass, 134, 77. DOI: 10.1007/s00214-015-1668-9. https://doi.org/10.1007/s00214-015-1668-9

Monajjemi, M. (2014). Metal-doped graphene layers composed with boron nitride-graphene as an insulator: a nano-capacitor, Journal of Molecular Modeling, 20, 2507. https://doi.org/10.1007/s00894-014-2507-y

Mehring, M., (1978) Principles of High Resolution NMR in Solids, 2nd.ed, Springer Verlag, Berlin, H. W. Spiess, In NMR Basic Principles and Progress; P. Diehl, E. Fluck, R. Kosfeld, Eds.; Springer Verlag, Berlin, Vol. 15

Monajjemi, M. (2012). Quantum investigation of non-bonded interaction between the B15N15 ring and BH2NBH2 (radical, cation, anion) systems: a nano molecular motor. Struct Chem, 23,551 -580. https://doi.org/10.1007/s11224-011

$-9895-8$

Monajjemi, M. (2013). Non bonded interaction between BnNn (stator) and BN B(rotor) systems: A quantum rotation in IR region. Chemical Physics, 425, 29-45. https://doi.org/10.1016/j.chemphys. 2013.07.014

Monajjemi, M., Boggs, J.E. (2013). A New Generation of BnNn Rings as a Supplement to Boron Nitride Tubes and Cages. J. Phys.Chem. A, 1 17, 1670-1684. https://doi.org/10.1021/jp312073q

Monajjemi, M., Ghiasi, R., Ketabi, S., Passdar, H., Mollaamin, F. (2004) A theoretical study of metalstabilised rare tautomers stability: $\mathrm{N} 4$ metalated cytosine $\left(\mathrm{M}=\mathrm{Be}^{2+}, \mathrm{Mg}^{2+}, \mathrm{Ca}^{2+}, \mathrm{Sr}^{2+}\right.$, and $\left.\mathrm{Ba}^{2+}\right)$ in gas phase and different solvents, Journal of Chemical Research , 1, 11

Nexo Revista Científica / Vol. 33, No. 01, pp. 121-136 / Junio 2020 
Monajjemi, M., Ghiasi, R., Seyed Sadjadi, M.A. (2003) Metal-stabilized rare tautomers: N4 metalated cytosine $\left(\mathrm{M}=\mathrm{Li}^{+}, \mathrm{Na}^{+}, \mathrm{K}^{+}, \mathrm{Rb}^{+}\right.$and $\left.\mathrm{Cs}^{+}\right)$, theoretical views . Applied Organometallic Chemistry, 17, 8, 635-640

Naghsh, F., Monajjemi, M., Zare, K, (2018), A conceptual model of microtubules as a macrobiological molecule and Quantum Consciousness, Biointerface Research in Applied chemistry, Volume 8, Issue 6, $3758-3763$

Nishimori, I., Vullo, D., Innocenti, A., Scozzafava, A., Mastrolorenz, A., Supuran.C.T., (2005).Bioorg Med Chem Lett., 15,3828-3833.

Ozoemena K, Stefan R. (2005) Enantioselective potentiometric membrane electrodes based on $\alpha-, \beta$ - and gamma-cyclodextrins as chiral selectors for the assay of 1-proline. Talanta , 66:501 -504.

Ogden, R.C., Flexner, C.W., (2001) Protease inhibitors in AIDS therapy. New York, U.S.A: Marcel Dekker.

Pham, T.T., Monajjemi, M., Dang, D.M.T., Mollaamin, F., Khakpour, A., Dang, C.M., (2019), An overview of bio-interface electrolyte and Li2FePO4F as cathode in Li-ion batteries, Biointerface Research in Applied chemistry, Volume 9, Issue 2, 3866 - 3873, https://doi.org/10.33263/BRIAC92.866873

Pham, T.T., Monajjemi, M., Dang, D.M.T., Mollaamin, F., Dang, C.M., (2019), Reaction of cell membrane bilayers "as a variable capacitor" with G-protein: a reason for neurotransmitter signaling, Biointerface Research in Applied chemistry, Volume 9, Issue 2, 2019, 3874 - 3883, https://doi.org/10.33263/BRIAC92.874883

Pham, T.T., Monajjemi, M., Dang, D.M.T., Mollaamin, F., Dang, C.M., (2019) Nano-capacitors as batteries including graphene electrodes and Ga-N mixed with biopolymers as insulator, Biointerface Research in Applied chemistry, Volume 9, Issue 1, 2019, 3806 - 3811, https://doi.org/10.33263/BRIAC91.806811

Pham, T.T., Monajjemi, M., Mollaamin, F., Dang, C.M., (2020), Advanced materials for family of fuel cells: a review of polymer electrolyte membrane, Biointerface Research in Applied chemistry, Volume 10, Issue 1, 4853 - 4863, https://doi.org/10.33263/BRIAC101.853863

Ray P. (1961) Complex Compounds of Biguanides and Guanylureas with Metallic Elements.Chem. Rev. 1961, 61: 313-359

Sekaran B, Rani P. (2010) Development and validation of spectrophotometric method for the determination of DPP4 inhibitor, Sitagliptin in its pharmaceutical dosage forms. Int. J. Pharm. Sci. 2 (4): 138-142.

Schmidtchen, F.P., Berger, M., (1997) Artificial Organic Host Molecules for Anions, Chem. Rev. 97, 16091646 (1997). 